This is a preprint version of the paper: Jurjako, Marko. (forthcoming). Is

Psychopathy a Harmful Dysfunction. Biology and Philosophy.

\title{
Is psychopathy a harmful dysfunction?
}

\begin{abstract}
In their paper "Is psychopathy a mental disease?", Thomas Nadelhoffer and Walter SinnottArmstrong have argued that according to any plausible account of mental disorder, neural and psychological abnormalities correlated with psychopathy should be regarded as signs of a mental disorder. I oppose this conclusion by arguing that at least on a naturalistically grounded account, such as Wakefield's 'Harmful Dysfunction' view, currently available empirical data and evolutionary considerations indicate that psychopathy is not a mental disorder.
\end{abstract}

Keywords: psychopathy, mental disorder, harmful dysfunctions, frequency-dependent selection, life-history theory

\section{Introduction}

Psychopathy is a categorization that involves peculiar affective and interpersonal personality styles that reoccur across different cultures (Cooke 1998). The social problems posed by psychopathy are most notably related to their antisocial behavior. Psychopathic individuals are disproportionately more likely than any other group of people to commit a crime and violently recidivate (Kiehl and Hoffman 2011). In this respect, they put enormous pressure on our moral, legal, and economic systems. Thus, the problem we are facing is that of finding an appropriate social response to individuals with exacerbated psychopathic traits. 
This is a preprint version of the paper: Jurjako, Marko. (forthcoming). Is

Psychopathy a Harmful Dysfunction. Biology and Philosophy.

Whether psychopathy is a mental illness or disorder is relevant for determining social policy (Skeem et al. 2011). For instance, concerning legal accountability, the diagnosis of psychopathy tends be treated as an aggravating factor. Defendants classified as psychopaths tend to be more severely punished for their crimes than non-psychopaths (Aspinwall, Brown, and Tabery 2012). However, if psychopathy is a mental illness or disorder then it should probably be regarded as a mitigating factor when deciding how much people categorized as psychopaths should be held accountable for their crimes (Glenn, Laufer, and Raine 2011).

In the literature, the question whether psychopathy should be regarded as a mental disorder has received surprisingly little attention. ${ }^{1}$ Nadelhoffer and Sinnott-Armstrong (2013) provide a seminal and comprehensive discussion of this issue. Without committing themselves to any particular account, they argue that, according to all plausible accounts of mental disease, neural and psychological abnormalities correlated with psychopathy constitute a mental disorder. The main aim of this paper is to discuss whether psychopathy should be conceptualized as a disorder according to all plausible accounts of mental disorder. I situate the debate within Nadelhoffer and Sinnott-Armstrong's (2013) discussion. I argue that at least according to one plausible account of mental disorder, the Harmful Dysfunction view, there is good reason for thinking that psychopathy is not a mental disorder.

\footnotetext{
${ }^{1}$ In fact, this question has received little attention across disciplines. In psychology, the notable exceptions are Krupp et al. (2012, 2013) and Leedom et al. (2012), while in philosophy, Malatesti (2014) and Reimer (2008) provide preliminary discussions of this issue.
} 
This is a preprint version of the paper: Jurjako, Marko. (forthcoming). Is Psychopathy a Harmful Dysfunction. Biology and Philosophy.

According to this view, a condition is a disorder if it is caused by a harmful dysfunction in internal mechanisms, where the proper function of a mechanism is determined by its selective evolutionary history. To show that psychopathy is not a mental disorder, I will rehearse some of the well-known arguments for thinking that psychopathy might be an evolutionary adaptation. The novel contribution of my discussion consists in integrating recent evidence and often disregarded theoretical considerations pertaining to the issue whether psychopathic traits should be construed as adaptations. In particular, I will argue that recent empirical evidence and theoretical considerations suggest that psychopathic individuals might be psychologically and biologically equipped for instantiating a reproductive strategy that is maintained by a frequency-dependent selection and is prosperous in harsh environments where it pays off to exhibit antisocial personality traits (cf. Mealy 1995). Moreover, against some objections, I will argue that these empirical and theoretical considerations on balance support the idea that psychopathy is not a mental disorder according to the Harmful Dysfunction account. ${ }^{2}$

I proceed as follows. In the next section, I indicate reasons why the issue whether psychopathy is a mental disorder is important in terms of public policy. In section 3, I provide an overview of neuropsychological peculiarities correlated with psychopathy that might indicate that people with psychopathic traits are mentally disordered. In section 4, I provide a general overview of Nadelhoffer and Sinnott-Armstrong's argument that psychopathy is a mental illness. In Section 5, I situate the discussion within Jerome Wakefield's Harmful Dysfunction view of mental disorder. In section 6, against some

\footnotetext{
${ }^{2}$ Thanks to two anonymous reviewers for pressuring me to be more precise about the scope of my discussion.
} 
This is a preprint version of the paper: Jurjako, Marko. (forthcoming). Is

Psychopathy a Harmful Dysfunction. Biology and Philosophy.

objections, I defend the view that psychopathic traits might be construed as evolutionary adaptations to an ecological or social niche. This view will explain in what sense abnormalities (in the statistical sense) correlated with psychopathic traits might be seen as 'designed' features of a certain lifestyle and hence not as harmful dysfunctions.

\section{Psychopathy and the social response}

Determining whether psychopathy is a mental disorder is important for several reasons. The first concerns the issue of the appropriate social response to psychopathic offenders. This issue is often formulated in terms of moral and criminal responsibility of the psychopaths (see, e.g. Malatesti and McMillan 2010; Kiehl and Sinnott-Armstrong 2013; see, also, Anonymous 2018). If a psychopathic offender satisfies the criteria for moral and criminal responsibility, then she is culpable for her wrongdoing and a suitable target for punishment. Alternatively, if she is to be found unaccountable, as prescribed by our moral and penal systems, then the appropriate social response would perhaps include medical or other kind of treatment rather than punishment. Nadelhoffer and Sinnott-Armstrong give a clear statement of this issue:

If psychopaths are merely immoral, then they should (or at least may) be held fully responsible for their criminal conduct, just like normal criminals. On the other hand, if psychopathy is a mental disease, then individuals who commit crimes as a result of their psychopathy arguably should be eligible for an insanity defense, much like individuals who commit crimes as a result of schizophrenia or perhaps kleptomania. (Nadelhoffer and SinnottArmstrong 2013, p. 230) 
This is a preprint version of the paper: Jurjako, Marko. (forthcoming). Is

Psychopathy a Harmful Dysfunction. Biology and Philosophy.

Across countries, legal requirements for being accountable usually require that the relevant incapacity stems from a mental disorder (Anonymous 2018). ${ }^{3}$ In that regard, it is surprising that more authors do not discuss the question whether psychopathy is a mental illness (cf. Reimer 2008).

It could be argued that this question has already been resolved. Namely, the Diagnosticstatistical manual of mental disorders (DSM-5, APA 2013) mentions psychopathy under the classification of antisocial personality disorder (ASPD). ASPD denotes a heterogeneous class of people who exhibit exacerbated forms of antisocial behavior. Psychopathy differs from ASPD because it is characterized by peculiar affective and interpersonal styles (Blair, Mitchell and Blair 2005; Glenn and Raine 2014; Hare 2003; see next section). Nonetheless, psychopathy is also often characterized by antisocial behavior. In this respect and especially as related to prison populations, psychopathy can be considered as a subset of ASPD (Hare 2003). Thus, it could be argued that if ASPD should be conceptualized as a mental disorder then psychopathy should be as well.

However, this way of arguing is not satisfying. Many categories of DSM have been contested on various grounds (see, e.g. Wakefield 2011a). ASPD in particular has been contentious because it seems to medicalize immoral behavior (see, e.g. Sadler 2008). I will not discuss whether it is problematic to use moral categories when building psychiatric

\footnotetext{
${ }^{3}$ In general, it is important to keep in mind that mental disorders in legal proceedings are relevant to the extent that they affect legally relevant abilities of an agent (Sifferd and Hirstein 2013). So not every diagnosis of a mental disorder will be relevant for excusing some behavior. However, since antisocial behavior is strongly correlated with (or according to some it is even a part of) the construct of psychopathy (Hare 2003), then if psychopathy were a disorder, we would have strong grounds for explaining psychopaths' tendency towards antisocial behavior as effects of legally relevant dysfunctional capacities.
} 
This is a preprint version of the paper: Jurjako, Marko. (forthcoming). Is

Psychopathy a Harmful Dysfunction. Biology and Philosophy.

classifications. But, it needs to be emphasized that even by DSM's own lights categories such as ASPD and psychopathy can be contentious. After defining mental disorder, the authors of DSM state that "[s]ocially deviant behavior (...) and conflicts that are primarily between the individual and society are not mental disorders unless the deviance or conflict results from a dysfunction in the individual" (APA 2013, p. 20). Thus, from the perspective of DSM-5 and other similar diagnostic manuals, the crucial question is whether psychopathy is characterized with internal dysfunctions that warrant the label of "mental disorder". In fact, some authors have argued that psychopaths are characterized by psychological and biological dysfunctions and therefore should be considered as mentally disordered or even legally insane (see, e.g. Glenn, Raine, and Laufer 2011; Nadelhoffer and Sinnott-Armstrong 2013).

Thus, in the next section, I give an overview of abnormalities related to psychopathy. ${ }^{4}$ Then, I discuss whether these abnormalities should be construed as dysfunctions indicating that psychopathy is a mental disorder.

\section{Abnormalities in the psychopath: An overview}

The most widespread tool used for diagnosing psychopathy in the forensic settings is Robert Hare's Psychopathy Checklist-Revised (PCL-R; for other measures of psychopathy, see, e.g. Fowler and Lilienfeld 2013). PCL-R conceptualizes psychopathy in terms of 20 items denoting four sets of correlated traits, regarded as facets (Hare 2003). Psychopaths typically show negative interpersonal traits; they are glib, manipulative, and

\footnotetext{
${ }^{4}$ Here and in what follows the intended sense of "abnormality' is statistical and not normative.
} 
This is a preprint version of the paper: Jurjako, Marko. (forthcoming). Is Psychopathy a Harmful Dysfunction. Biology and Philosophy.

pathological liars (the Interpersonal facet). Their emotional responses are diminished; for example, they are callous, lack empathy and do not show remorse for their misconduct (the Affective facet). Traits falling under these two facets tend to correlate, thus they are collectively denoted as Factor 1. In addition, psychopaths tend to lead an impulsive and irresponsible lifestyle; for example, they typically do not have realistic long-term goals, they are impulsive, prone to boredom, seek stimulation, and lead a parasitic lifestyle (the Lifestyle facet). Finally, they exhibit antisocial behavior; for example, psychopathy is correlated with the early onset of juvenile delinquency, criminal versatility, and recidivism (the Antisocial facet). The latter two facets comprise Factor 2 of PCL-R. On particular items a person can score 0,1 , or 2 points, depending to what degree a trait can be ascribed to the person. This is determined by a trained psychologist in a semi-structured interview. Thus, maximal score is 40 , and pragmatically determined cut-off score for being a psychopath is 30 and 25 in North America and Europe, respectively.

Discussions on whether psychopathy is a mental disorder are fraught with different complexities. It is thought that Factor 1 traits differentiate psychopathic individuals from other groups falling under ASPD (Hare 2003). Thus, Factor 1 traits are conceptualized as the core psychopathy traits. On the other hand, empirical and psychometric research indicates that even the construct of psychopathy denotes a further heterogeneous group of people (Anonymous 2017). In fact, psychopathic traits are dimensionally distributed in populations and there may be no clear outline delineating psychopaths from nonpsychopaths (Lilienfeld 2013). ${ }^{5}$ Relying on PCL-R pragmatically solves this problem since

\footnotetext{
${ }^{5}$ In addition, some studies indicate that psychopathic personality traits (Factor 1) can be exhibited without antisocial behavior (Factor 2) (see, e.g. Ishikawa et al. 2001). Thus, some authors adopt a distinction between
} 
This is a preprint version of the paper: Jurjako, Marko. (forthcoming). Is Psychopathy a Harmful Dysfunction. Biology and Philosophy.

it postulates a cut-off point (Anonymous 2017). However, it has to be kept in mind that since psychopathic traits are dimensional and can be more or less expressed in general populations, it is more appropriate to talk about psychopathic individuals, rather than psychopaths.

Authors arguing that psychopathic individuals are mentally disordered and thus should be held less accountable for their wrongful behavior, insist that correlations of psychopathic traits with antisociality result from dysfunctional mental and/or brain mechanisms (see, e.g. Glenn, Raine, and Laufer 2011; Nadelhoffer and Sinnott-Armstrong 2013; Sifferd and Hirstein 2013). In what follows, I give an overview of peculiarities related to neural or mental mechanisms that might be relevant in this regard.

There are two dominant neurocognitive conceptualizations of psychopathy. One set of theories attempts to account for psychopathic traits in terms of affective abnormalities, while the other does so in terms of cognitive or attentional abnormalities.

According to the affect-based accounts, most notably developed by James Blair and colleagues, psychopathic traits can be explained by abnormalities in the processing of emotional stimuli (Blair, Mitchell, and Blair 2005). The main contention is that psychopaths have an abnormal capacity to experience, recognize, and learn from emotional cues, most notably fear and sadness, which leads to statistically aberrant development of other morally relevant emotions, such as guilt and empathy. There are indications that psychopaths have difficulty forming associations via fear conditioning (Lykken 1995). In

\footnotetext{
successful and unsuccessful psychopaths (Sifferd and Hirstein 2013). However, given that this distinction is still rather contested and neuropsychologically not well-grounded (see Maes and Brazil 2013), I will not rely on it in my discussion.
} 
This is a preprint version of the paper: Jurjako, Marko. (forthcoming). Is

Psychopathy a Harmful Dysfunction. Biology and Philosophy.

normal subjects, associative learning is performed on the basis of using affective stimuli to regulate one's behavior. A fearful face is normally a cue for stopping the aggressive behavior towards that person. One explanation why psychopathic individuals are prone to aggressive behavior is that their amygdala and neural circuits connected to it process information differently. So, it might be that psychopaths do not detect or experience negative affective cues that should be regulating their behavior. This evidence is accompanied by neurobiological data indicating that psychopaths exhibit abnormal activation patterns in the ventromedial and orbitofrontal prefrontal cortex, and their connections to subcortical areas, most notably the amygdala, that underpin associative and reinforcement learning (Blair 2008; Kiehl 2006).

According to the attention-based accounts, psychopathy is correlated with cognitive peculiarities. These accounts are based on a large number of studies done by Joseph Newman and colleagues. ${ }^{6}$ The core idea is that psychopaths' behavioral and affective abnormalities are relative to contextual factors, namely they often depend on the focusing of attention (Koenigs and Newman 2013). For example, psychopaths' abnormalities in associative learning are not restricted to affective stimuli; they extend to neutral stimuli when they are outside of their primary focus of attention (Larson et al. 2013). For instance, individuals with psychopathic traits are less accurate in recognizing sad and fearful facial expressions, because they do not focus on the relevant regions of the eyes and mouth. But when these face regions are in their primary focus then they normally recognize those emotions (for a review, see Koenigs and Newman 2013). Furthermore, it has been

\footnotetext{
${ }^{6}$ The most notable account is the Response Modulation Hypothesis developed by Newman and colleagues. For this and other variants of the RMH, see, e.g. Koenigs and Newman (2013).
} 
This is a preprint version of the paper: Jurjako, Marko. (forthcoming). Is

Psychopathy a Harmful Dysfunction. Biology and Philosophy.

discovered that other affect-based abnormalities disappear when psychopaths' attention is properly focused. They show normal fear-potentiated startle reflex, passive avoidance learning, emotion recognition, and, most interestingly, amygdala activation when their attention is suitably directed to the task relevant stimuli (Larson et al. 2013). ${ }^{7}$

These affective and attentional abnormalities are standardly characterized as dysfunctions, disorders, or impairments, implying that there is something wrong with psychopaths' mental and neuropsychological capacities. Normally, this loose talk about interesting statistical abnormalities as dysfunctions is legitimate and scientists in their ordinary empirical work are not guilty of misusing the language of functions and dysfunctions. However, from an analytic perspective, this loose talk can lead to a lack of clarity and induce misunderstandings. Here it must be emphasized that not every statistical difference amounts to a dysfunction, disorder, or a disease (Boorse 1977), let alone a dysfunction that affects capacities that are relevant for responsibility (Anoynmous 2018). Nevertheless, Nadelhoffer and Sinnott-Armstrong (2013) argue that according to any plausible theory of mental illness, the reviewed peculiarities indicate that psychopathy is a mental disorder.

\section{The problem of defining "mental disorder"}

Nadelhoffer and Sinnott-Armstrong's (from now on N\&S-A) (2013) recognize that there is no overarching consensus on how to conceptualize mental illness (see also Bolton 2008;

\footnotetext{
${ }^{7}$ For a neurobiologically grounded model that attempts to provide a unified account of attentional and affective peculiarities correlated with psychopathy, see Moul, Dadds, and Killcross (2012).
} 
This is a preprint version of the paper: Jurjako, Marko. (forthcoming). Is

Psychopathy a Harmful Dysfunction. Biology and Philosophy.

Varga 2015). ${ }^{8}$ A common ground is provided by DSMs' definition of mental disorder. According to DSM-5, a mental disorder is "a clinically significant disturbance in an individual's cognition, emotion regulation, or behavior that reflects a dysfunction in the psychological, biological, or developmental processes", that is "usually associated with significant distress or disability in social, occupational, or other important activities" (APA 2013, p. 20). However, DSMs typically do not explain more specifically when a disturbance reflects a dysfunction as opposed to a normal variation, or in other words what grounds the norms that determine when a psychological or biological process is malfunctioning (Bolton 2008).

In the literature, different authors have construed differently the notion of dysfunction and grounds for claiming that some condition is a mental disorder. For example, some authors are eliminativists about mental illness. According to Thomas Szasz (1961), there are no mental diseases as such. Either a psychiatric condition is caused by a malfunctioning organ and thus is a bodily disease, or if it is not then it is just a "problem in living" and thus not a real disease. Szasz's type of eliminativism is directed against political and other misuses of psychiatry that have been common in the past. For instance, in the $19^{\text {th }}$ century, Drapetomania (or runaway slave syndrome) was considered to be a mental illness characterizing black people who run away from slave farms (Cartwright 1851). The overly reductionist spirit of Szasz' eliminativism prompted other authors to adopt more inclusive accounts of mental illness. Some authors endorse social constructionist views that emphasize value-ladeness of the concept of disease (see, e.g. Cooper 2002; Varga 2015).

\footnotetext{
8 I follow Nadelhoffer and Sinnott-Armstrong (2013) in using 'illness', 'disease' and 'disorder' interchangeably.
} 
This is a preprint version of the paper: Jurjako, Marko. (forthcoming). Is

Psychopathy a Harmful Dysfunction. Biology and Philosophy.

According to these views, whether a condition is a disease depends on how much it deviates from some culturally determined value-based standard of sanity or health.

In contrast, other authors contend that mental illness is not value-laden and that it can be defined or explicated in naturalistic terms (for a discussion, see Kingma 2014). According to one such account, the objectivist biomedical model, a condition is a disease if it negatively affects individuals' biological fitness by disrupting normal function in some mental or bodily mechanism (Boorse 1977; Kendell 1975; for a recent statement of this view, see Boorse 2014). Still other authors combine normative and objectivist-naturalist views (Murphy 2006). ${ }^{9}$ According to one of the most influential hybrid models, the Harmful Dysfunction account, whether a condition is a disease depends on valuejudgments about how harmful the condition is given some socially adopted standard, but only if this harmful condition is a consequence of an independently specifiable objective dysfunction in biological or psychological mechanisms (see, e.g. Wakefield 1992). N\&SA's (2013, p. 235) strategy is to argue that, for each of these accounts, either psychopathy is a mental disease or else the account is implausible on independent grounds. ${ }^{10}$

\footnotetext{
${ }^{9}$ For a thorough discussion of different possible combinations of naturalist and normativist views about mental illness, see Kingma (2014).

${ }^{10}$ It might be objected that N\&S-A do not give an exhaustive list of accounts of mental illness. Relevantly for the present discussion, they do not consider evolutionary or functional approaches to psychiatry, according to which some condition might be a consequence of an evolutionary adaptation and still be a disorder (see, e.g. Adriaens and DeBlock 2011; Murphy 2005; Nesse and Williams 1997). For instance, different symptoms of anxiety disorders might have been adaptive in ancestral environments which were presumably more unsecure, lacking in resources, and dangerous. But, in modern environments being overly anxious might lead to maladaptive psychological conditions and behaviors. However, I think that N\&S-A rightly do not discuss such approaches to mental disorders. Evolutionary approaches to disorders, insofar as they differ from Boorse's or Wakefield's accounts, arguably should be construed as providing "explanatory models of dysfunctional, maladaptive behaviour (...)" (Bolton 2008, 126-127, emphasis added). As such
} 
This is a preprint version of the paper: Jurjako, Marko. (forthcoming). Is Psychopathy a Harmful Dysfunction. Biology and Philosophy.

For instance, they argue that purely social constructionist accounts are implausible because, on the one hand, they make disorders such as schizophrenia culture-relative, while on the other hand, they reify diseases such as drapetomania (N\&S-A 2013, p. 239). Also, they indicate problems related to a purely biomedical model of mental illness. Roughly, according to this model, a disease is a state that reduces an individual's biological fitness (see, e.g. Kendell 1975). N\&S-A argue that this model unjustifiably overgeneralizes. For instance, let us suppose that homosexuality lowers a person's fitness because it causes preferences inimical to reproduction. In that case homosexuality would be a disease. However, even if this were the case, N\&S-A (2013, p. 243; see also Cooper 2002, p. 270) argue that homosexuality would not be a disease because it is not harmful to a person, i.e. it does not cause distress or disabilities to a person. ${ }^{11}$ Thus, they contend that a better account of disease should also be sensitive to values and norms that govern our conceptions of harmfulness.

Jerome Wakefield's Harmful Dysfunction (HD) view of mental disorders provides such a hybrid account of disorder. Although N\&S-A do not endorse any of the reviewed accounts, they seem to find HD plausible, or at least they do not rule it out as implausible (N\&S-A 2013, p. 245, ft. 9). More importantly, they provide important reasons for thinking that according to this view psychopathy should also be classified as a mental illness (2013,

they presuppose criteria of what constitutes a mental disorder rather than determining them (see also Wakefield 1992, p. 374). Thus, in principle one might combine them with normativist, naturalist or hybrid accounts.

11 This criticism might be resisted. However, given my focus on the Harmful Dysfunction view and space limitations, I will not discuss it. For a more recent defense of the biomedical model, see Boorse (2014). For criticisms and modifications to Boorse's model, see, for instance, Hausman (2012), and Schwartz (2007). 
This is a preprint version of the paper: Jurjako, Marko. (forthcoming). Is

Psychopathy a Harmful Dysfunction. Biology and Philosophy.

pp. 243-245). In the next section, I introduce Wakefield's HD account. Then, against objections made by N\&S-A and other authors, I will provide plausible reasons for thinking that psychopathy is not a mental disorder according to HD.

\section{The Harmful Dysfunction view of mental disorders}

The core of Wakefield's HD view is provided in the following oft-cited passage (see, also, Wakefield 2000, 2011b):

A condition is a disorder if and only if (a) the condition causes some harm or deprivation of benefit to the person as judged by the standards of the person's culture (the value criterion), and (b) the condition results from the inability of some internal mechanism to perform its natural function, wherein natural function is an effect that is part of the evolutionary explanation of the existence and structure of the mechanism (the explanatory criterion). (Wakefield 1992, p. 384)

The account has two components: the harmful component encodes the value criterion referring to socially based value judgments that define the well-being of a person. The dysfunction component purports to encode the value-neutral condition that explains the disorder as a disruption in the functioning of internal mechanisms.

Wakefield construes the notion of dysfunction in terms of the so-called selected effects theory of functions (SE). According to SE, to say that the function of some trait $\mathrm{X}$ is to produce an effect $\mathrm{Z}$ amounts to providing a causal explanation according to which $\mathrm{X}$ was 
This is a preprint version of the paper: Jurjako, Marko. (forthcoming). Is Psychopathy a Harmful Dysfunction. Biology and Philosophy.

favored by natural selection because it tended to produce the effect Z. ${ }^{12}$ To illustrate, the function of a heart is to pump blood, and not to produce beating sounds, because hearts were naturally selected for pumping blood. The fact that they also make beating sounds is just a side effect of that function. According to this view a trait is dysfunctional if it does not produce evolutionary selected effects. ${ }^{13}$

The application of SE within the HD account can be illustrated as follows. If a person is sterile due to some inherited condition or acquired injury then this condition involves a reproductive malfunction. Since we normally judge such a dysfunction as being harmful to an individual, we would categorize this condition as an illness. However, if sterility is a consequence of one's deliberate choice to take birth control pills or undergo a vasectomy then we would not consider it as harmful, and therefore this condition would not constitute an illness.

The Harmful Dysfunction view is not without its critics. In fact, HD has been criticized as being overly restrictive, epistemically inadequate, and giving counterintuitive disease classifications (see, e.g. Faucher 2012; Murphy and Woolfolk 2000). So why rely on HD? For one, it is important to keep in mind the dialectics of the present discussion. N\&S-A

\footnotetext{
${ }^{12}$ In other words, according to SE, the function of a trait is conferred to it by past selective processes. Organisms that had these traits survived and reproduced more than other organisms that did not possess traits with these effects. For an overview of theories of biological function, see, e.g. Garson (2016); Sterelny and Griffths (1999, pp. 220-221).

${ }^{13}$ One question facing selected-effects theories is how far in the evolutionary past one needs to look to determine the function of a trait (see Varga 2015, 180, ft. 13). A plausible answer is given by the so-called 'modern history' account of function (Godfrey-Smith 1994; see also Sterelny and Griffiths 1999, pp. 218220). According to this view, the function of a trait is determined by the most recent selective pressures that are responsible for maintaining the trait in a population. For its use in the explication of the concept of disorder, see Griffiths and Matthewson (2018).
} 
This is a preprint version of the paper: Jurjako, Marko. (forthcoming). Is

Psychopathy a Harmful Dysfunction. Biology and Philosophy.

argue that, according to all plausible accounts of mental disorder, psychopathy should be classified as a mental disorder. Since they do not rule out HD as implausible, dialectically it seems an appropriate move to investigate whether this really is the case. Second, many authors agree that HD at least in broad contours provides a good framework for thinking about the nature of disorder. ${ }^{14}$ HD fits well with recent developments in neuropsychiatry and the conceptualization of diseases in diagnostic manuals, such as the DSM (Murphy 2006, p. 35). Moreover, HD seems to be dominant in the psychopathological research. For instance, Robert Hare writes that if psychopathy is an "adaptive life strategy" it would indicate that their neurological peculiarities are not symptoms of neuropathology (Hare 2013, p. vii). In addition, Krupp and colleagues (2012) agree with Hare and argue that psychopathy is not a mental disorder, while Leedom and Hartoonian-Almas (2012) argue that psychopathy is a mental disorder (for a response, see Krupp et al. 2013). Importantly, both parties in the discussion explicitly rely on Wakefield's HD account of mental disorder. For these reasons, it is important to investigate whether psychopathy really is a disorder according to HD.

\subsection{Are psychopathic traits underpinned by biological dysfunctions?}

\footnotetext{
${ }^{14}$ For recent defenses of the naturalistic accounts of disease that are structurally similar to Wakefield's HD, see Griffiths and Matthewson (2018) and Matthewson and Griffiths (2017). It should be noted, though, that unlike Wakefield (1992), who is trying to give a conceptual analysis of the concept of disease, Griffiths and Matthewson (2018) aim to provide an explication in the Carnapian sense or a theoretical regimentation of the concept of disease that will be useful for integrating theoretical and practical research in medicine and related fields.
} 
This is a preprint version of the paper: Jurjako, Marko. (forthcoming). Is

Psychopathy a Harmful Dysfunction. Biology and Philosophy.

If psychopathy is a mental illness according to $\mathrm{HD}$, then it is a harmful condition stemming from a dysfunctional internal mechanism(s). It seems easy to establish that psychopathy satisfies the harm criterion. On this point, N\&S-A write:

Psychopaths are unable to lead normal, productive, healthy lives. ... [T] usually live much of their lives in prison, so they are deprived of freedom, which society values. (...) [T] hey are often driven to lead nomadic lifestyles devoid of normal relationships with friends, family, and romantic partners. (...) Furthermore, (...) their lives are often (...) deprived of achievements that are valued by society. (...) Thus, psychopathy perfectly exemplifies Wakefield's value criterion. (N\&S-A 2013, pp. 244-245)

To the extent that the harm condition involves subjective distress, psychopathy does not satisfy it; psychopathic individuals do not suffer from being psychopaths, nor they normally seek help to stop being psychopaths (Hare 1999, 2003). Nonetheless, their typical antisocial behavior deprives them of socially valuable goods. Thus, for the sake of argument, we can grant that they satisfy the harm condition. However, if the dysfunction condition is not also satisfied, it follows that psychopathy is not a mental illness. HD presupposes an etiological view of functions; therefore, neural, cognitive, and affective abnormalities do not amount to dysfunctions if their pattern of activity supports some naturally evolved function. Indeed, Wakefield confirms this contention for the case of psychopathy:

But what if even the most extreme cases of antisocial personality, involving classic psychopathic symptomatology, turned out to be naturally selected "niche" adaptations? In this unlikely event, our current intuitions would be 
This is a preprint version of the paper: Jurjako, Marko. (forthcoming). Is

Psychopathy a Harmful Dysfunction. Biology and Philosophy.

wrong, and (...) we would exchange our disorder attributions for attributions of normal (though problematic) variation. Antisocials would be different and at odds with others in the way that, say, men and women are different and sometimes at odds, without either being disordered. (Wakefield 2000, p. 260)

In fact, there is an influential tradition in psychopathy research that explains psychopathic traits exactly in terms of adaptations to certain ecological and social 'niches' (see, e.g. Glenn, Kurzban, and Raine 2011; Jonason, Koenig, and Tost 2010; Krupp et al. 2013; Lalumière, Mishra, and Harris 2008; Lykken 1995; Mealey 1995; Meloy et al. 2018). Moreover, N\&S-A (2013, pp. 243) take seriously and leave open the possibility that psychopathy might be an evolutionary adaptation. Nonetheless, they offer important reasons for thinking that even if psychopathy is an adaptation still it could be underpinned by biological dysfunctions. In the next section, I will introduce empirical and theoretical considerations that make plausible the claim that psychopathy is an adaptation and thus not a mental disorder according to HD. Then I will show how these considerations undermine the reasons expounded by N\&S-A for thinking that psychopathy is underpinned by dysfunctional internal mechanisms.

\section{Psychopathic traits as niche adaptations}

In general, a minimal condition for a trait to be an evolutionary adaptation is that the trait is retained in a population by natural selection (see Lauder 1996, pp. 61-62). Normally, natural selection will affect evolution of a trait if there is a heritable variation of that trait influencing the organism's fitness (see, e.g. Sterelny and Griffiths 1999, sec. 10.6). In other 
This is a preprint version of the paper: Jurjako, Marko. (forthcoming). Is Psychopathy a Harmful Dysfunction. Biology and Philosophy.

words, there must be some variation in the trait that influences survival and reproduction and can be passed on to the next generation. A famous example is Darwin's Galápagos finches, whose variation in beak size presents a heritable trait that, depending on the environment and food type, influences their fitness. If finches feed on seeds on the ground, then we tend to see more finches with shorter and robust beaks because such beak shapes are more adaptive. If they feed on seeds from cacti, then we see longer and sharper beaks.

In general, if a trait reduces fitness then, ceteris paribus, its frequency over time will decline. If it increases fitness then, ceteris paribus, its frequency will increase or stay balanced. Of course, this is an oversimplified scenario because often cetera are not paria (see Gluckman, Beedle, and Hanson 2009, pp. 43-44; Lauder 1996). There are always other evolutionary processes, such as random drift, migration or mutations, that might influence the representation of a trait in a population. Hence a fitness deleterious trait will not always be depleted, nor will a fitness beneficial trait necessarily increase in frequency. ${ }^{15}$ Bearing in mind these caveats, let us examine some reasons for thinking that psychopathic traits might be adaptations.

In general, patterns of variation in personality traits might have an important impact on a person's fitness, by influencing “evolutionarily relevant outcomes, such as survival, mating success, offspring production, and parenting" (Buss 2009, p. 360; see also Penke, Denisson, and Miller 2007). The traits that people differ on include:

\footnotetext{
${ }^{15}$ For other issues and complexities related to inferring the activity of natural selection from the apparent design of a feature, see Gould and Lewontin (1979), Lauder (1996), and Sterelny and Griffiths (1999, sec. 10.3 and 10.5).
} 
This is a preprint version of the paper: Jurjako, Marko. (forthcoming). Is Psychopathy a Harmful Dysfunction. Biology and Philosophy.

individual differences in personality characteristics (e.g., dominance vs. submissiveness; agreeableness vs. aggressiveness), general intelligence and more specific abilities (e.g., spatial location vs. spatial rotation abilities), mating strategies (e.g., short term vs. long term), political attitudes (e.g., liberal vs. conservative), religiosity (high vs. low), body type (e.g., mesomorph, endomorph), mate value, and many others. (Buss 2009, p. 360)

Studies indicate that generally personality traits that people differ on are moderately heritable (Buss 2009; Penke, Denisson, and Miller 2007). In this regard, core psychopathic traits do not seem to be different (Glenn and Raine 2014, p. 23). Initial twin studies have found that callous/unemotional traits are $\sim 40 \%-50 \%$ heritable (Blonigen et al. 2003, 2005). Moreover, in a large sample of twins (more than 7000 children), Viding and colleagues found that more than $60 \%$ of core psychopathic traits are heritable (Larsson, Viding, and Plomin 2008; Viding et al. 2005, 2008). ${ }^{16}$ In addition, psychopathic traits seem to be constant in human populations across times and cultures (Cooke 1998). They can even be meaningfully discerned in chimpanzees, indicating that psychopathic traits reoccur in primate phylogenetic lineages (Latzman et al. 2016).

\footnotetext{
${ }^{16}$ It should be noted that these heritability rates do not mean that the expression of psychopathic traits is genetically determined regardless the environment (Glenn and Raine 2014, p. 23; for a discussion of heritability of antisocial behavior, see Tabery 2014, ch. 7). In fact, heritability rates indicate the proportion of variance of a phenotypic trait that can be attributed to genetic as opposed to environmental factors and these rates are always relative to populations under scrutiny. Thus, it should be kept in mind that the proper explanation of heritability of phenotypic traits, even those that have high heritability rates, will always reflect average genetic and environmental interactions in a sampled population (Tabery 2014). This means that in some individuals genetic factors, while in others environmental conditions will have a greater contribution to exhibiting psychopathic traits (Glenn and Raine 2014, p. 23).
} 
This is a preprint version of the paper: Jurjako, Marko. (forthcoming). Is

Psychopathy a Harmful Dysfunction. Biology and Philosophy.

Given that psychopathic traits present a constant and stabile variation in human personality, some authors speculate about the evolutionary underpinnings of these traits and how the adaptive value might vary with their differential expression among individuals. Some psychopathic traits as described by the PCL-R, such as promiscuous sexual behavior and many short term marital relationships, plausibly could have a positive impact on the "evolutionarily relevant outcomes". In fact, there is preliminary evidence that, under some conditions, psychopathic traits are positively correlated with reproductive success. A global study on women with psychopathic traits found positive correlations between psychopathic traits and reproductive success (Neumann et al. 2012). Another study with criminal psychopaths found that people with higher interpersonal and affective traits as measured by the PCL-R, especially those who had harsh childhoods (in particular, where family background includes substance abuse, maltreatment and criminal behavior of parents), positively correlate with the number of children, which is taken as a proxy of reproductive success (Međedović et al. 2017).

It could be remarked that a trait's being adaptive (i.e. increasing fitness in current environments) is not necessary for being an adaptation (i.e. favored by natural selection in the past) (see Sterelny and Griffiths 1999 , pp. 217-218). ${ }^{17}$ For instance, reading might increase fitness in current environments, but probably there was no selection specifically for this ability and thus is not an adaptation. Nonetheless, current adaptive utility is normally taken as evidence of adaptation. This is in line with the abductive nature of the adaptationist reasoning, which is normally based on a defeasible inference from current

\footnotetext{
17 This point is raised by an anonymous reviewer because HD presupposes an etiological theory of function.
} 
This is a preprint version of the paper: Jurjako, Marko. (forthcoming). Is

Psychopathy a Harmful Dysfunction. Biology and Philosophy.

adaptive utility of a trait to a hypothesis about selective processes that might have produced it (Sterelny and Griffiths 1999, pp. 232, 241-242). Conversely, its absence is taken as an incentive to search for alternative explanations (Keller and Miller 2006). For instance, paradigmatic examples of mental disorders, such as schizophrenia, major depression and autism, are negatively correlated with fitness (Power et al. 2013). This justifies searching for non-adaptationist explanations because, ceteris paribus, natural selection removes traits that reduce fitness. Since the opposite seems to be the case with psychopathy, it warrants speculating about the selective pressures sustaining those traits (Glenn, Kurzban, and Raine 2011; Mealy 1995). Thus, in the next section, I discuss a model of selection that can account for the past and current adaptive value of psychopathic traits.

\subsection{A distal mechanism for maintaining psychopathic traits}

A prominent account of the evolution of psychopathic traits is based on the model of balancing selection (N\&S-A 2013, p. 242; see also Glenn, Kurzban, and Raine 2011; Lalumière, Mishra, and Harris 2008; Mealy 1995). As we have seen, there is a heritable variation in personality traits. One important mechanism for sustaining this variability might be the balancing selection (Penke, Denisson, and Miller 2007; see also ft. 21 below). Importantly for the present discussion, balancing selection may occur when a phenotype's fitness depends on the frequency of other phenotypes in a population (Mealy 1995). Formal studies in game theory indicate that antisocial behavior can be adaptive when its prevalence in the population is low (Colman and Wilson 1997; Harpending and Sobus 1987; cf. Murphy 2005, p. 759). The basic idea is that in a population consisting mostly of cooperative agents, it becomes beneficial to play the cheater strategy, i.e. to take advantage of other agents' cooperative, helpful or reciprocating dispositions without paying the cost 
This is a preprint version of the paper: Jurjako, Marko. (forthcoming). Is

Psychopathy a Harmful Dysfunction. Biology and Philosophy.

of cooperation. ${ }^{18}$ Being 'antisocial' in this formal sense is adaptive when the prevalence of non-cooperators or defectors is low enough not to be detected and retaliated against. When applied to psychopathy and translated into real-life evolutionary currency,

these models presume that the general population is predominantly cooperative, honest, and trusting, which allows a small proportion of individuals to capitalize on this benevolence by cheating — stealing valuable resources and engaging in promiscuous sexual behavior (Mealey 1995). As the proportion of cheaters (i.e., psychopaths) inches up in frequency, however, society at large becomes more vigilant, enacting countermeasures against their depredations (e.g., imprisonment), thereby maintaining their frequency at a low level. (Skeem et al. 2011, p. 112)

Although mostly theoretical, the frequency-dependent model of selection provides a schema of a mechanism explaining how psychopathic traits might have been retained in human populations (for a general discussion of optimality models in evolutionary theory, see Sterelny and Griffths 1999, sec. 10.6). It can also be related to predictions about behavioral, neuropsychological, and structural features of populations that instantiate the antisocial strategy (Glenn, Kurzban, and Raine 2011). In what follows, I will offer some data that support these predictions.

First, with respect to the structural features, Colman and Wilson (1997) have estimated that the frequency of non-cooperators should be less than $2 \%$ for it to be an adaptive

\footnotetext{
${ }^{18}$ Antisocial behavior as a defection strategy is often modeled as the prisoner's dilemma game (Harpending and Sobus, 1987). However, some studies model psychopathic traits as implementing the hawk strategy in the dove-hawk game (Colman and Wilson, 1997). In the empirical literature, there is evidence that psychopathic personality is related to both the cheater and hawk strategies (Book and Quinsey, 2004).
} 
This is a preprint version of the paper: Jurjako, Marko. (forthcoming). Is

Psychopathy a Harmful Dysfunction. Biology and Philosophy.

strategy, that is, to be maintained in an evolutionary equilibrium of behavioral strategies.

In line with this, studies indicate that the estimated number of psychopaths in the general population is around 1\% (Neumann and Hare 2008).

Second, having psychopathic personality and behavioral traits enables one to instantiate the antisocial strategy with positive fitness effects (see also subsection 6.3 below). For instance, psychopaths' promiscuous and early onset of sexual behavior and many short-term marital relationships could increase the probability of reproductive and mating success; glibness/superficial charm would enable psychopaths to navigate social structures undetected, allow them to deceive others, present themselves as socially attractive and attract or poach potential mates; impulsivity and fearlessness might be functional for taking advantage of immediate opportunities; being unempathic, callous, guiltless and unremorseful enables them to disregard potentially stressful stimuli, to lead a careless life, to disregard parental responsibilities and carelessly pursue their often antisocial goals, such as using their aggression to take advantage of others (see Glenn, Kurzban, and Raine 2011, p. 374; Meloy et al. 2018).

It could be objected that some traits often ascribed to psychopaths, such as poor longterm planning and impulsivity (Hare 2003), denote cognitive deficits that count against the adaptationist explanation. For instance, Dominic Murphy (2005, pp. 760-761) seems to argue that these traits are signs of instrumental irrationality, and thus cannot be sustained by natural selection. This reasoning is not sound, however. The notion of instrumental rationality can have different ramifications, and it is false that according to all ramifications these psychopathic traits will turn out to be irrational (see, e.g. Anonymous 2016; for an overview of notions of instrumental rationality, see Kacelnik 2006). Moreover, for the 
This is a preprint version of the paper: Jurjako, Marko. (forthcoming). Is

Psychopathy a Harmful Dysfunction. Biology and Philosophy.

argument to work, the relevant sense of instrumental irrationality should involve having cognitive traits that reduce fitness. However, being impulsive and not having long-term plans is not necessarily negatively correlated with fitness (Međedović et al. 2017). In fact, in uncertain and harsh environments, where life-expectancy is short, they might be byproducts of an adaptive life strategy (see below subsection 6.3). ${ }^{19}$

Third, studies in behavioral economy indicate that psychopaths might be neuropsychologically adapted to 'cheating' and other immoral behavioral strategies. Studies undertaken with incarcerated and non-incarcerated psychopaths confirm that psychopathic individuals more often defect in one-shot and repeated prisoner's dilemma games (Curry, Jones, and Viding 2011; Mokros et al. 2008). Moreover, fMRI brain studies indicate that when delivering moral judgments and making strategic decisions, psychopaths 'employ' brain areas related to emotionally detached processes (Vieira et al. 2014). In neurotypical subjects, a decision to cooperate activates the amygdala (automaticemotional reactions), and the decision to defect involves greater activity in the dorsolateral prefrontal cortex (associated with cognitive control and regulation of prepotent impulses). In individuals with higher psychopathy traits, the pattern of activations seems to be reversed (Rilling et al. 2007). This evidence nicely dovetails with the predictions of the adaptationist hypothesis. The lower activation rates of the amygdala and other affectrelated brain areas arguably enable psychopaths to play the antisocial strategy in the cooperative surroundings.

\footnotetext{
${ }^{19}$ Murphy (2005, p. 270) suggests in passing that impulsivity and poor long-term planning might be seen as “adaptive cognitive styles". I develop this point within the Life History theory in subsection 6.3. Thanks to an anonymous referee for pressing me to address this issue.
} 
This is a preprint version of the paper: Jurjako, Marko. (forthcoming). Is

Psychopathy a Harmful Dysfunction. Biology and Philosophy.

It might be objected that this type of balancing mechanism cannot plausibly be applied to explain the persistence of psychopathic traits "because many of them do spectacularly badly in life" (Nesse 2001, p. 43). According to some estimations "approximately $93 \%$ of adult male psychopaths in the United States are in prison, jail, parole, or probation" (Kiehl and Hoffman 2011, p. 355). Of course, their being often incarcerated does not imply that their current fitness is diminished, in the sense that they fail to procreate or that their opportunities for reproduction are significantly reduced. As mentioned above, preliminary evidence indicates that core psychopathic traits are positively correlated with reproduction in a prison population (Međedović et al. 2017). Moreover, Hare mentions that it is not even uncommon for incarcerated individuals with psychopathic traits to seduce and take advantage of the personnel working at forensic institutions (see, e.g. Hare 1998, pp. 148149).

Nonetheless, this objection might put pressure on the adaptationist explanation of psychopathy because, as Murphy has argued (2005, pp. 759-760), if psychopaths are so easily detected in big modern societies, then it is unlikely that their genes might have been retained by natural selection given that early social environments in which humans evolved were comprised of small and isolated societies in which detection was easier than in today's larger societies. In this regard, David Cooke gives an interesting example how small Inuit communities tended to respond to people with psychopathic traits: they would "invite them to go hunting and, when no one was looking, push them off the ice" (Cooke 1998, p. 15).

This objection is not conclusive because detection in small societies does not imply that reproductive success of such individuals or their opportunities for reproduction would be significantly reduced. In fact, Inuit concept of Kunlangeta, an analogue of psychopathy, 
This is a preprint version of the paper: Jurjako, Marko. (forthcoming). Is

Psychopathy a Harmful Dysfunction. Biology and Philosophy.

is defined by many success verbs. Cooke writes that Kunlangeta, among other things, denotes a person who "repeatedly lies and cheats and steals things and does not go hunting and, when the other men are out of the village, takes sexual advantage of many women (...)" (Cooke 1998, p. 15). Behavioral characterization of such people indicates that they take advantage of many opportunities to play the antisocial strategy. And there is no reason to suppose that they do not manage to spread their genes, before they get caught and 'eliminated'.

\subsection{Dysfunctions in proximal mechanisms?}

N\&S-A (2013, p. 243) recognize the possibility that psychopathic traits might be evolutionary adaptations. They entertain this possibility in the context of Christopher Boorse's (1977) biomedical model of disease, which they reject on independent grounds (see above section 4). There they maintain that although psychopathic traits might be adaptive, it is still open whether neural mechanisms, such as the amygdala, are failing to perform their natural functions, which according to them is "enough to make psychopathy a dysfunction and a mental disease" (2013, p. 243; see, also, Leedom and HartoonianAlmas 2012; Nesse 2001, p. 43). Murphy goes a step further and argues that these considerations undermine the adaptationist hypothesis itself "because the cognitive mechanisms underlying what is putatively an adaptive strategy are ones that appear to be far from functional" (Murphy 2005, p. 760). Specifically, he indicates that PCL-R traits, such as impulsivity and lack of long-term plans, might be underlined by cognitive deficits that are caused by "information-processing problems in frontal systems" (Murphy 2005, p. 760). 
This is a preprint version of the paper: Jurjako, Marko. (forthcoming). Is

Psychopathy a Harmful Dysfunction. Biology and Philosophy.

Arguably, one function of the amygdala and the neural circuitry connecting it to the prefrontal cortex evolved to register affective, especially fearful stimuli, calculate its expected value, and trigger appropriate responses that are acquired via associative learning (Moul, Dadds, and Killcross 2012). Additionally, they might play an important role in developing empathic reactions that underpin socially adaptive behavior (Blair, Mitchell, and Blair 2005). Thus, the abnormal activation patterns of the amygdala and related circuitry in frontal lobes might indicate that according to HD, psychopaths' harmful behavior results from dysfunctions in internal mechanisms.

This conclusion would be premature, however. First, different studies have shown that abnormal activations of frontal and paralimbic regions in psychopaths' brains depend on contextual factors (Koenigs and Newman 2013; Larson et al. 2013). In fact, Larson and colleagues (2013) have recorded normal amygdala activation in psychopaths while responding to threatening stimuli. Moreover, Hoppenbrouwers, Bulten, and Brazil (2016) argue that psychopaths normally experience subjective fear. Instead, it seems that their peripheral perceptual systems differently process fear-related stimuli. This indicates that psychopaths do not lack capacities underpinned by the prefrontal cortex and amygdala; rather, it suggests that their conditions of activation are different (Blair 2007).

Second, and relatedly, according to HD's conception of function "many apparent dysfunctions associated with psychopathy (for example, reduced empathy, lack of guilt and impulsivity)" should not be seen as dysfunctions, rather they can "be better understood as design features" (Del Giudice 2014, p. 269; see, also, Faucher 2012, pp. 32-33; Lalumière, Mishra, and Harris 2008; Mealy 1995). Moreover, from this perspective "functional differences observed during performance of a task might reflect the use of different 
This is a preprint version of the paper: Jurjako, Marko. (forthcoming). Is

Psychopathy a Harmful Dysfunction. Biology and Philosophy.

strategies in performance of the task, while structural differences might be a case of 'use it or lose it"” (Neumann and Hare 2010, p. 110).

In line with this view, the abovementioned neuroeconomic studies provide evidence that the amygdala function in psychopathic individuals might be plausibly construed as an adaptation supporting the antisocial lifestyle strategy. This game-theoretic perspective provides an explanation how untypical brain activation patterns in psychopaths might underlie functionally and evolutionary adaptive choices in the frequency-dependent sense (Lalumière, Mishra, and Harris 2008). Thus, the differential activation patterns of amygdala can be seen as part of "designed features" necessary for reaping the benefits of having blunted affect and unempathic attitudes. For instance, lower responsiveness to fearful and sad stimuli and lower activation rates of the amygdala might reflect an adaptation to environments where morally or socially undesirable lifestyles pay-off, and which these traits can only hinder. Similarly, the diminished connectivity between the ventromedial and orbitofrontal cortex, and other cortical and subcortical areas may enable psychopathic individuals to disregard the expected effects of punishment and release resources to be used in focused, goal-directed behavior (Mealy 1995). Thus, if these abnormal activation levels are effects of adaptations, then they cannot be considered as dysfunctions according to HD.

\subsection{Life-history strategy and longevity/reproduction trade-offs}

Despite the reviewed considerations, N\&S-A might insist that although, for instance, the underactivated amygdala may be fitness beneficial in terms of reproduction, it is likely that it also decreases longevity by making them less responsive to fearful and potentially 
This is a preprint version of the paper: Jurjako, Marko. (forthcoming). Is

Psychopathy a Harmful Dysfunction. Biology and Philosophy.

threatening cues. This might be taken as evidence that the amygdala is dysfunctional in psychopaths. For instance, they write that the

amygdala hypoactivity might have advantages in enabling psychopaths to be promiscuous. Nonetheless, it has disadvantages in decreasing longevity. However these considerations weigh against each other, their amygdala is not performing the general function for which the amygdala evolved or, at least, not at the level for which the amygdala was selected. (N\&S-A 2013, p. 243).

$\mathrm{N} \& \mathrm{~S}-\mathrm{A}$ seem to be arguing that if activation patterns of some brain areas are correlated with decreased longevity this indicates that they are not performing their function correctly.

However, this reasoning is not valid. N\&S-A might be right that the activation pattern of the amygdala in psychopaths enhances reproductive success at the expense of decreasing longevity. Nonetheless, this trade-off between reproduction and longevity is not ipso facto a sign of dysfunction. Otherwise, for instance, being male could be considered a disease. Mortality rate for males in puberty is three times higher than for females (Nesse 2001, p. 43). It is thought that higher levels of testosterone might play a role in male's greater disposition towards riskier behavior. Despite this, it would be wrong to think that normal levels of testosterone in adolescent males indicate a dysfunction simply because they increase mortality. N\&S-A seem to recognize this point since they write that the solution to the problem whether psychopathy is adaptive or dysfunctional can "depend on whether the increased reproduction due to promiscuity and manipulativeness outweighs the decreased longevity due to violence and stimulation seeking” (N\&S-A 2013, p. 242). However, when it comes to amygdala they surprisingly seem to disregard the importance 
This is a preprint version of the paper: Jurjako, Marko. (forthcoming). Is

Psychopathy a Harmful Dysfunction. Biology and Philosophy.

of this trade-off between longevity and reproduction. In particular, they seem to claim that the hypoactivity of amygdala is a sign that it is malfunctioning "even if [the amygdala] did increase reproduction overall" (N\&S-A 2013, p. 243). ${ }^{20}$

There is a general reason why trade-offs between longevity and reproduction cannot be taken as evidence that there is some dysfunction present. Trade-offs between longevity and reproduction present universal ecological problems that organisms must solve in order to successfully adapt to their environments (Stearns 1989). This idea is synthesized in the part of evolutionary theory called the Life-History theory (LHT). LHT has been developed in evolutionary ecology to explain how adaptations to different ecological niches produce diversity among the life histories of different species and individual organisms during different life stages (for an overview, see Stearns 2000). Recently, this framework has been applied to human differences in personality traits (Buss 2009), evolutionary approaches to medicine (Gluckman, Beedle, and Hanson 2009), the evolution of psychopathic traits (Glenn, Kurzban, and Raine 2011), and to clarify notions of biological function and dysfunction in general (Griffiths and Mathewson 2018).

In general, this research indicates that there is a trade-off between the time and energy that an organism must invest to solve different environmental challenges related to its fitness (Stearns 1989). Specifically, trade-offs must be made when fitness increase in one important LH trait involves fitness decrease in another. Importantly, there is a basic negative genetic correlation (an adaptive trade-off) between longevity and early reproduction; increased selection for extended lifespan is correlated with a decrease in

\footnotetext{
${ }^{20}$ Thanks to an anonymous referee for directing my attention to this tension in N\&S-A's discussion.
} 
This is a preprint version of the paper: Jurjako, Marko. (forthcoming). Is

Psychopathy a Harmful Dysfunction. Biology and Philosophy.

early (and overall) reproduction. This fact is true of fruit flies as well as of more complex organisms (Stearns 2000; see also Gluckman, Beedle, and Hanson 2009, Box 5.2). Specifically, extended longevity is correlated with delayed reproduction, greater investments in parental effort and a smaller number of offspring. These behaviors are adaptive in predictable and resource-rich environments. On the other hand, in unpredictable, stressful, and resource-poor environments life expectancy is lower, it becomes adaptive to engage earlier in sexual activity and to invest less in offspring, which is correlated with quantitatively greater reproductive success (Stearns 1989).

Studies indicate that the expression of psychopathic traits is positively correlated with poor parental care and childhood maltreatment (Gao et al. 2010). Poor parental care and childhood maltreatment constitute harsh and stressful early environments where expected shorter life spans can be offset by early reproduction (Glenn, Kurzban, and Raine 2011; Jonason, Koenig, and Tost 2010). Those are also environments where psychopathic traits may play a beneficial role as 'safety belts' against potentially fitness diminishing influences and where it can pay off to play the antisocial strategy (Jonason, Koenig, and Tost 2010; Jonason, Li, and Buss 2010; Krupp et al. 2013; Međedović et al. 2017). In particular, core affective and interpersonal traits enable psychopathic individuals to become sexually active early in life, have many short term sexual relationships, poach other people's mates (remember "Kunlangeta"), not lose time on rearing offspring, be resilient to stressful events, and use their aggression to take advantage of others (Meloy et al. 2018). Moreover, given that unpredictable and resource poor environments induce uncertainty about the future, they also induce a trade-off between behavioral strategies involving immediate against delayed gratification. In unpredictable and poor environments, where 
This is a preprint version of the paper: Jurjako, Marko. (forthcoming). Is

Psychopathy a Harmful Dysfunction. Biology and Philosophy.

future life prospects are uncertain and life-expectancy is short, it makes sense to develop traits that will maximize immediate reward. From this perspective, PCL-R traits such as poor long-term planning and impulsivity, can be construed as "adaptive cognitive styles" (cf. Murphy 2005, p. 760). In fact, such behavioral traits are characterized by discounting the future and proneness to seize the immediate opportunities (Hare 2003). Thus, they can be conducive to a life strategy that is adaptive in unpredictable environments.

Here the main point of introducing the considerations based on LHT is to show why N\&S-A's claim that trade-offs between reproduction and longevity indicate dysfunction in the amygdala is not convincing. ${ }^{21}$ In fact, from a LHT perspective, the existence of fitness relevant differential neurological and psychological profiles among different people are to be expected. As argued before, the peculiar activation patterns of amygdala and related neural circuitry in psychopaths can be seen as adaptations to an environment where it pays off to engage in the antisocial lifestyle and that is sustained by the balancing selection. As we have seen this life strategy can be beneficial in environments where life expectancy is lower and thus it pays more to invest in reproductive efforts (Glenn, Kurzban, and Raine 2011). Since the amygdala's role in psychopathy might be to enable such a life strategy,

\footnotetext{
${ }^{21}$ The argumentation in this section should not be read as separate from the argument that psychopathic traits are maintained by a balancing selection. The LHT is a general framework for theorizing about the adaptive challenges that organisms need to solve across life-cycles to maximize their fitness. LHT presupposes that there is a heritable variability underpinning important LH traits (such as personality traits influencing one's fitness). Frequency-dependent selection is an important mechanism that might account for such variability across different environments (Penke, Denissen, and Miller 2007). In our case, it explains how the heritable variation underlying psychopathic and nonpsychopathic personality traits is maintained in human populations. Thanks to an anonymous reviewer for indicating the need to make clearer the connection between LHT and frequency-dependent selection.
} 
This is a preprint version of the paper: Jurjako, Marko. (forthcoming). Is

Psychopathy a Harmful Dysfunction. Biology and Philosophy.

we do not have grounds for claiming that it is malfunctioning, even if it is correlated with reduced longevity (Del Gudice 2014).

\section{Conclusion}

In their thought-provoking paper, Nadelhoffer and Sinnott-Armstrong (2013) argued that that according to every plausible account of mental illness psychopathy should be classified as disordered. On the contrary, I argued that at least on Wakefield's Harmful Dysfunction view there is not enough evidence to consider psychopathic traits as symptoms of a mental disorder. The argument relied on a defense of the plausibility of the hypothesis that psychopathic traits instantiate an adaptive life strategy that is maintained by frequencydependent selection. I maintain that until this hypothesis is proven false we should be reluctant in judging that psychopathic traits present harmful dysfunctions. Since the discussion is based on theoretical and empirical studies, it surely does not provide the final word on this issue. Future research should shed additional light on the potential functional and dysfunctional underpinnings of psychopathic traits that should be taken into account when thinking about our ascriptions of mental disorder status to psychopathic individuals.

\section{References}

Adriaens PR, De Block, A (eds) (2011) Maladapting minds: philosophy, psychiatry, and evolutionary theory. New York: Oxford University Press.

American Psychiatric Association (2013) Diagnostic and statistical manual of mental disorders: DSM-5. 5th ed. Washington, D.C: American Psychiatric Association

Aspinwall LG, Brown TR, Tabery J (2012) The double-edged sword: does biomechanism increase or decrease judges' sentencing of psychopaths? Science 337: 846-849

Blair RJ (2007) The amygdala and ventromedial prefrontal cortex in morality and psychopathy. Trends in Cognitive Sciences 11:387-392 
This is a preprint version of the paper: Jurjako, Marko. (forthcoming). Is

Psychopathy a Harmful Dysfunction. Biology and Philosophy.

Blair RJ (2008) The amygdala and ventromedial prefrontal cortex: functional contributions and dysfunction in psychopathy. Philosophical Transactions of the Royal Society $B$ 363: $2557-2565$

Blair RJ, Mitchell MG, Blair KS (2005) The psychopath: emotion and the brain. Oxford: Blackwell

Blonigen DM, Carlson SR, Krueger RF, Patrick CJ (2003) A twin study of self-reported psychopathic personality traits. Personality and Individual Differences 35: 179-197

Blonigen DM, Hicks B, Krueger R, Patrick CJ, Iacono W (2005) Psychopathic personality traits: heritability and genetic overlap with internalizing and externalizing pathology. Psychological Medicine 25: 637-648

Bolton D (2008) What is mental disorder? An essay in philosophy, science, and values. Oxford: Oxford University Press

Book AS, Quinsey VL (2004) Psychopaths: cheaters or warrior-hawks? Personality and Individual Differences 36: 33-45

Boorse C (1977) Health as a theoretical concept. Philosophy of Science 44: 542-573

Boorse C (2014) A second rebuttal on health. The Journal of Medicine and Philosophy 39: $683-724$

Buss DM (2009) How can evolutionary psychology successfully explain personality and individual differences? Perspectives on Psychological Science 4: 359-366

Cartwright S (1851) Report on the diseases and peculiarities of the negro race. DeBow's Review XI

Colman AM, Wilson CJ (1997) Antisocial personality disorder: an evolutionary game theory analysis. Legal and Criminological Psychology 2: 23-34

Cooke DJ (1998) Psychopathy across cultures. In: Cooke DJ, Forth AE, Hare RD (eds) Psychopathy: theory, research and implications for society. Springer, Dordrecht, pp $13-46$

Cooper R (2002) Disease. Studies in History and Philosophy of Science Part C: Studies in History and Philosophy of Biological and Biomedical Sciences 33: 263-282

Curry O, Chester Jones M., Viding E (2011) The psychopath's dilemma: the effects of psychopathic personality traits in one-shot games. Personality and Individual Differences 50: 804-809 
This is a preprint version of the paper: Jurjako, Marko. (forthcoming). Is

Psychopathy a Harmful Dysfunction. Biology and Philosophy.

Del Giudice M (2014) An evolutionary life history framework for psychopathology.

Psychological Inquiry 25: 261-300.

Faucher L (2012) Evolutionary psychiatry and nosology: prospects and limitations. Baltic International Yearbook of Cognition, Logic and Communication 7: 1-64

Fowler KA, Lilienfeld and SO (2013) Alternatives to Psychopathy Checklist-Revised. In:

Kiehl KA, Sinnott-Armstrong WP (eds) Handbook on psychopathy and law,

Oxford University Press, Oxford, pp 34-57

Gao Y, Raine A, Chan F, Venables PH, Mednick SA (2010) Early maternal and paternal bonding, childhood physical abuse and adult psychopathic personality.

Psychological Medicine 40: 1007-1016

Garson J (2016) A Critical Overview of Biological Functions. Springer, Dordrecht

Glenn AL, Kurzban R, Raine A (2011) Evolutionary theory and psychopathy. Aggression and Violent Behavior 16: 371-380

Glenn AL, Laufer WS, Raine A (2011) Is it wrong to criminalize and punish psychopaths? Emotion Review 3: 302-304.

Glenn AL, Raine A (2014) Psychopathy: an introduction to biological findings and their implications. New York University Press, New York, London

Gluckman PD, Beedle A., Hanson MA (2009) Principles of evolutionary medicine. Oxford University Press, Oxford

Godfrey-Smith P (1994) A modern history theory of functions. Noûs 28: 344-362.

Gould SJ, Lewontin RC (1979) The spandrels of San Marco and the panglossian paradigm: a critique of the adaptationist programme. Proceedings of The Royal Society of London B 205: 581-598.

Griffiths PE, Matthewson J (2018) Evolution, dysfunction, and disease: a reappraisal. The British Journal for the Philosophy of Science 69: 301-327

Hare RD (1999) Without conscience. The Guilford Press, New York, London

Hare RD (2003) The Hare Psychopathy Checklist Revised (2nd ed.). Toronto: Multi-Health Systems

Hare RD (2013) Foreword. In: Kiehl KA, Sinnott-Armstrong WP (eds) Handbook on psychopathy and law. Oxford University Press, Oxford pp vii-ix 
This is a preprint version of the paper: Jurjako, Marko. (forthcoming). Is

Psychopathy a Harmful Dysfunction. Biology and Philosophy.

Harpending HC, Sobus J (1987) Sociopathy as an adaptation. Ethology and Sociobiology, $8,63 \mathrm{~S}-72 \mathrm{~s}$

Hausman DM (2012) Health, naturalism, and functional efficiency. Philosophy of Science 79: $519-541$

Hoppenbrouwers SS, Bulten BH, Brazil IA (2016) Parsing fear: a reassessment of the evidence for fear deficits in psychopathy. Psychological Bulletin 142: 573-600

Ishikawa SS, Raine A, Lencz T, Bihrle S, Lacasse L (2001) Autonomic stress reactivity and executive functions in successful and unsuccessful criminal psychopaths from the community. Journal of Abnormal Psychology 110: 423-432

Jonason PK, Koenig BL, Tost J (2010) Living a fast life: the dark triad and life history theory. Human Nature 21: 428-442

Jonason PK, Li NP, Buss DM (2010) The costs and benefits of the dark triad: implications for mate poaching and mate retention tactics. Personality and Individual Differences 48: $373-378$

Kacelnik A (2006) Meanings of rationality. In: Hurley S, Nudds M (eds) Rational animals? Oxford University Press, Oxford, pp 87-106

Keller MC, Miller G (2006) Resolving the paradox of common, harmful, heritable mental disorders: which evolutionary genetic models work best? Behavioral and Brain Sciences 385-404

Kendell RE, (1975) The concept of disease and its implications for psychiatry. British Journal of Psychiatry 127: 305-315

Kiehl KA (2006) A cognitive neuroscience perspective on psychopathy: evidence for paralimbic system dysfunction. Psychiatry Research 142: 107-128

Kiehl KA, Hoffman MB (2011) The criminal psychopath: history, neuroscience, and economics. Jurimetrics 51: 355-397

Kiehl KA, Sinnott-Armstrong W (eds) (2013) Handbook on psychopathy and law. Oxford University Press, Oxford

Kingma E (2014) Naturalism about health and disease: adding nuance for progress. The Journal of Medicine and Philosophy 39: 590-608

Koenigs M, Newman JP (2013) The decision making impairment in psychopathy: psychological and neurobiological mechanisms. In: Sinnott-Armstrong WP, Kiehl 
This is a preprint version of the paper: Jurjako, Marko. (forthcoming). Is

Psychopathy a Harmful Dysfunction. Biology and Philosophy.

KA (eds) Handbook on psychopathy and law. Oxford University Press, Oxford, pp 93-106

Krupp DB, Sewall LA, Lalumière ML, Sheriff C, Harris GT (2012) Nepotistic patterns of violent psychopathy: evidence for adaptation? Frontiers in Psychology 3: 1-8

Krupp DB, Sewall LA, Lalumière ML, Sheriff C, Harris GT (2013) Psychopathy, adaptation, and disorder. Frontiers in Psychology 4: 1-5

Lalumière M, Mishra S, Harris GT (2008) In cold blood: the evolution of psychopathy. In:

Duntley J, Shackelford TJ (eds) Evolutionary forensic psychology. Oxford University Press, Oxford, pp 176-197

Larson CL, Baskin-Sommers AR, Stout DM, Balderston NL, Curtin JJ, Schultz DH, Kiehl KA, Newman JP (2013) The interplay of attention and emotion: top-down attention modulates amygdala activation in psychopathy. Cognitive, Affective, and Behavioral Neuroscience 13: 757-770

Larsson H, Viding E, Plomin R (2008) Callous-unemotional traits and antisocial behavior: genetic, environmental, and early parenting characteristics. Criminal Justice and Behavior 35: 197-211

Latzman RD, Drislane LE, Hecht LK, Brislin SJ, Patrick CJ, Lilienfeld SO, Freeman H. J, Schapiro SJ, Hopkins WD (2016) A chimpanzee (Pan Troglodytes) model of Triarchic Psychopathy Constructs: development and initial validation. Clinical Psychological Science: A Journal of the Association for Psychological Science 4: $50-66$

Lauder GV (1996) The argument from design. In: Rose M, Lauder GV (eds) Adaptation. Academic Press, San Diego, pp 55-91

Leedom LJ, Hartoonian-Almas L (2012) Is psychopathy a disorder or an adaptation? Frontiers in Psychology 3: 1-3

Lilienfeld, SO (2013) Is psychopathy a syndrome? Commentary on Marcus, Fulton, and Edens. Personality disorders: theory, research, and treatment 4: 85-86

Lykken DT (1995) The antisocial personalities. Lawrence Erlbaum Associates, Hillsdale Maes JHR, Brazil IA (2013) No clear evidence for a positive association between the interpersonal-affective aspects of psychopathy and executive functioning. Psychiatry Research 210: 1265-1274 
This is a preprint version of the paper: Jurjako, Marko. (forthcoming). Is

Psychopathy a Harmful Dysfunction. Biology and Philosophy.

Malatesti L (2014) Psychopathy and failures of ordinary doing. Etica \& Politica / Ethics \& Politics 16: 1138-1152.

Malatesti L, McMillan J (eds) 2010. Responsibility and psychopathy: interfacing law, psychiatry and philosophy. Oxford University Press, Oxford

Matthewson J, Griffiths PE (2017) Biological criteria of disease: four ways of going wrong. The Journal of Medicine and Philosophy 42: 447-466

Mealey L (1995) The sociobiology of sociopathy: an integrated evolutionary model. Behavioral and Brain Sciences 18: 460-485

Međedović J, Petrović B, Želeskov-Đorić J, Savić M (2017) Interpersonal and affective psychopathy traits can enhance human fitness. Evolutionary Psychological Science 3: 306-315

Meloy, J R, Book A, Hosker-Field A, Methot-Jones T, Roters J (2018) Social, sexual, and violent predation: are psychopathic traits evolutionarily adaptive? Violence and Gender 5: 153-165

Mokros A, Menner B, Eisenbarth H, Alpers GW, Lange KW, Osterheider M (2008) Diminished cooperativeness of psychopaths in a prisoner's dilemma game yields higher rewards. Journal of Abnormal Psychology 117: 406-413

Moul C, Killcross S, Dadds MR (2012) A model of differential amygdala activation in psychopathy. Psychological Review 119: 789-806

Murphy D (2005) Can evolution explain insanity? Biology \& Philosophy 20: 745-766

Murphy D (2006) Psychiatry in the scientific image. The MIT Press, Cambridge, MA.

Murphy D, Woolfolk RL (2000) The harmful dysfunction analysis of mental disorder.

Philosophy, Psychiatry, and Psychology 7: 241-252

Nadelhoffer T, Sinnott-Armstrong W (2013) Is psychopathy a mental disease? In: Vincent NA (ed) Neuroscience and legal responsibility. Oxford University Press, Oxford, pp 229-255

Nesse RM, (2001) On the difficulty of defining disease: a Darwinian perspective.

Medicine, Health Care, and Philosophy 4: 37-46

Nesse RM, Williams G (1997) Are mental disorders diseases? In: Baron-Cohen S (ed)

The maladapted mind: classic readings in evolutionary psychopathology.

Psychology Press, Hove, pp 1-22 
This is a preprint version of the paper: Jurjako, Marko. (forthcoming). Is

Psychopathy a Harmful Dysfunction. Biology and Philosophy.

Neumann CS, Hare RD (2008) Psychopathic traits in a large community sample: Links to violence, alcohol use, and intelligence. Journal of Consulting and Clinical Psychology 76: 893-899

Neumann CS, Hare RD (2010) Psychopathy: assessment and forensic implications. In: Malatesti L, McMillan J (eds) Responsibility and psychopathy: interfacing law, psychiatry and philosophy. Oxford University Press, Oxford pp 93-124

Neumann CS, Schmitt DS, Carter R, Embley I, Hare RD (2012) Psychopathic traits in females and males across the globe. Behavioral Sciences and the Law 30: 557-574

Penke L, Denissen JJA, Miller GF (2007) The evolutionary genetics of personality. European Journal of Personality 21: 549-87

Power RA, Kyaga S, Uher R, MacCabe JH, Långström N, Landen M, et al (2013) Fecundity of patients with schizophrenia, autism, bipolar disorder, depression, anorexia nervosa, or substance abuse vs their unaffected siblings. JAMA Psychiatry 70: $22-30$

Reimer M (2008) Psychopathy without (the language of) disorder. Neuroethics, 1: 185198

Rilling JK, Glenn AL, Jairam MR, Pagnoni G, Goldsmith DR, Elfenbein HA, Lilienfeld SO (2007) Neural correlates of social cooperation and non-cooperation as a function of psychopathy. Biological Psychiatry 61: 1260-1271

Sadler JZ (2008) Vice and the diagnostic classification of mental disorders: a philosophical case conference. Philosophy, Psychiatry, \& Psychology 15: 1-17

Schwartz PH (2007) Defining dysfunction: natural selection, design, and drawing a line. Philosophy of Science 74: 364-385

Sifferd KL, Hirstein W (2013) On the criminal culpability of successful and unsuccessful psychopaths. Neuroethics 6: 129-140

Skeem JL, Polaschek DLL, Patrick CJ, Lilienfeld SO (2011) Psychopathic personality: bridging the gap between scientific evidence and public policy. Psychological Science in the Public Interest 12: 95-162

Stearns SC (1989) Trade-offs in life-history evolution. Functional Ecology 3: 259-268

Stearns SC (2000). Life history evolution: successes, limitations, and prospects. Naturwissenschaften 87: 476-486 
This is a preprint version of the paper: Jurjako, Marko. (forthcoming). Is

Psychopathy a Harmful Dysfunction. Biology and Philosophy.

Sterelny K, Griffiths PE (1999) Sex and death: an introduction to philosophy of biology.

University of Chicago Press, Chicago

Szasz TS (1961) The myth of mental illness. American Psychologist 15: 113-118

Tabery J (2014) Beyond versus: the struggle to understand the interaction of nature and nurture. MIT Press, Cambridge, Mass

Varga S (2015) Naturalism, interpretation, and mental disorder. Oxford University Press, Oxford, New York

Viding E, Jones A, Frick PJ, Moffitt TE, Plomin R (2008) Heritability of antisocial behaviour at nine-years: do callous-unemotional traits matter? Developmental Science 11: 17-22

Viding E, Blair RJR, Moffitt TE, Plomin R (2005) Evidence for substantial genetic risk for psychopathy in 7-year-olds. Journal of Child Psychology and Psychiatry 46: 592597

Vieira JB, Almeida PR, Ferreira-Santos F, Barbosa F, Marques-Teixeira J, Marsh AA (2014) Distinct neural activation patterns underlie economic decisions in high and low psychopathy scorers. Social Cognitive and Affective Neuroscience 9: 10991107

Wakefield JC (1992) The concept of mental disorder: on the boundary between biological facts and social values. American Psychologist 47: 373-388

Wakefield JC (2000) Spandrels, vestigial organs, and such: reply to Murphy and Woolfolk's “The Harmful Dysfunction analysis of mental disorder". Philosophy, Psychiatry, and Psychology 7: 253-270

Wakefield JC (2011a) DSM-5 proposed diagnostic criteria for sexual paraphilias: tensions between diagnostic validity and forensic utility. International Journal of Law and Psychiatry 34: 195-209

Wakefield JC (2011b) Darwin, functional explanation, and the philosophy of psychiatry. In: Adriaens RA, De Block A (eds) Maladapting minds: philosophy, psychiatry, and evolutionary theory. Oxford University Press, Oxford, pp 143-172 